\title{
UV Degradation Properties of a Virgin/Recycled Polymer Blend
}

\author{
Shigeru $\mathrm{YAO}^{\dagger}$, Aya TOMINAGA, Hiroshi SEKIGUCHI, and Eiichi TAKATORI ${ }^{*}$ \\ Department of Chemical Engineering, Fukuoka University \\ *TOSOH A\&R Center Co. Ltd.,
}

\begin{abstract}
We previously reported that the inner structures of thick $(>3 \mathrm{~mm})$ injection-molded test pieces of virgin polypropylene and recycled pre-consumer polypropylene were very different, even though their molecular and mechanical properties were almost the same. This difference was thought to be caused by the molding history of preconsumer polypropylene. Due to this difference in their internal structures, thin films $(<100 \mu \mathrm{m})$ of recycled preconsumer polypropylene were very brittle. By examining the degradation properties of these thin films in response to UV irradiation, we found that the toughness of these samples decreased exponentially in a UV irradiation timedependent manner. This dependence was almost the same in virgin and recycled samples, and we could superimpose of the results. We also found that the UV irradiation time-dependence was associated with the number of molecules that connected domains within the samples. In this study, we investigated the mechanical and UV irradiation timedependent properties of thick samples composed of a blend of virgin and recycled pre-consumer materials. We found that the mechanical properties of these non-irradiated samples were almost the same. However, the mechanical properties of irradiated samples were significantly different. We also found that this difference linearly depends on the blend ratio. These results suggest that specimens containing recycled polymers can exhibit very poor durability even though there are no differences in their non-irradiated mechanical properties.
\end{abstract}

Key Words: Recycle plastic / Tensile fracture energy / Shear induced crystallization / Tie molecule / Inner structure

\section{リサイクルポリマーブレンド系の UV 劣化特性について}

\author{
八尾 滋 ${ }^{\dagger}$, 冨永 亚矢, 関口 博史, 高取 永一 ${ }^{*}$
}

(原稿受理：2013 年 3 月 8 日)

\section{1. 緒 言}

再生プラスチックを単独で使用した場合, 力学特性が著 しく劣ることはよく知られており, そのために利用用途が

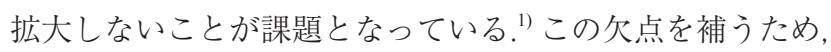
バージンポリマーと再生プラスチックを混ぜて製品化を行 うことがよくなされている。このような取り組みによりマテ リアルリサイクルを推進するために, グリーン購入法におい ては, 例えば文具類では再生プラスチックを重量で $40 \%$ 以 上使用されていることが基準となっており22，また（財）日 本環境協会が定めるエコマークでは, 原料として使用した再 生プラスチックの合計重量が，製品全体の重量割合で $70 \%$ 以上であることを，マークをつけるための条件としている.3) 前報において我々は, 射出成型時の副生物から得られたプ レコンシューマーリサイクルポリプロピレン (Pre-Consumer Recycling Polypropylene:Pre-RPP) は, そのバージン品 (Virgin

\footnotetext{
$\dagger$ To whom all correspondence should be addressed,

E-mail: shyao@fukuoka-u.ac.jp

福岡大学工学部 福岡市城南区七隈 8-19-1

* 株式会社東ソー分析センター 三重県四日市市霞 1-8
}

Polypropylene:VPP) と分子量や分子量分布あるいはFT-IRに よるカルボニル基とイソプロピル基の吸収比率に差がなく, 劣化しているとは言えないことを見出した。 またこれら試 料から成形された試験片の力学的特性は, 厚さが $3 \mathrm{~mm}$ 程度 より厚い場合には，ほとんど差がないことも見出している。 しかしながら液体チッソ中で破断した断面構造は, この両者 では全く異なっており，プレス成形した厚さ $100 \mu \mathrm{m}$ 程度の 薄膜フィルムの力学的特性は, Pre-RPP からの成形品が著し く劣ることも見出した. ${ }^{4}$ またこの原因は, Pre-RPPが成形時 に生成したせん断誘起結晶化 ${ }^{5-9}$ による特異な微細構造のた めと考えられることを指摘した. また力学特性の紫外線 (UV) 照射時間依存性が, VPP と Pre-RPP で重ね合わせが出来るこ とから, この力学特性の違いが系内のドメインを結合して いる分子数により整理できることを見出した。 しかしなが ら, より実用的な VPP と Pre-RPP のブレンドによる影響や, 厚さ $3 \mathrm{~mm}$ の試験片に対する紫外線劣化の影響などは未検討 であった。

今回我々は上記 Pre-RPP と VPP を所定のブレンド比で混 練し, $3 \mathrm{~mm}$ の試験片の作成を行い, SEMによる断面観察と, 引張特性評価およびその UV 照射依存性について検討したの で報告する。 


\section{2. 試料}

試料は前報で用いたものと同じ透明グレードのポリプロ ピレン (Virgin Polypropylene:VPP) と，その射出成型品の副生 物からペレタイズしたプレコンシューマーリサイクルポリ プロピレン (Pre-Consumer Recycling Polypropylene:Pre-RPP) を 用いた。これらを各々 10:0, 6:4, 3:7 および 0:10の重量ブ レンド比率で調製し， $3 \mathrm{~mm}$ 厚みの試験片 (JIS K7162-1B) を 射出成形し，引張試験に供した。またこれらを液体チッソ 中で破断し，その断面観察を行った。別途, VPP と Pre-RPP に関しては $100 \mu \mathrm{m}$ 厚みの試験片 (JIS K7113 2(1/3)) を $210{ }^{\circ} \mathrm{C}-2$ 分のプレス条件で作成し, 引張試験に供した。

\section{3. 結果と考察}

Figure 1 は VPP と Pre-RPP の $100 \mu \mathrm{m}$ 厚さのフィルムの引 張試験チャートを示す。試験結果のばらつきを考慮し，一つ の試料につき引張試験は 5 回行った。また Table I には Figure 1 で示した 5 回の引張試験結果から導き出した様々な引張特 性值を示す。ここで記載しているタフネス (Toughness) は, Figure 1 で示している力 - 変位曲線で囲まれた面積から算出 したエネルギー值を断面積で規格化した值で評価を行って いる。これらから明らかなように, Pre-RPPでは測定值が大 きくばらつくのに対し，VPPは安定した物性值が得られて いる。またPre-RPP はヤング率が若干高くなっているが，引 張伸びおよびタフネスともにVPP と比較して著しく小さく なっており，引張特性が劣ることが判る.
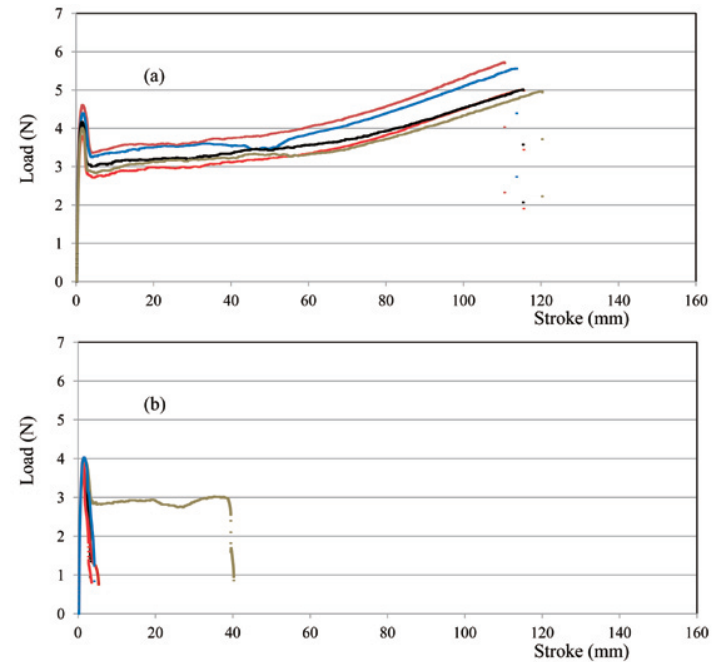

Fig. 1. Tensile test charts of VPP and Pre-RPP $100 \mu \mathrm{m}$ thick film. (a):VPP, (b):Pre-RPP

Table I. Tensile mechanical properties of $100 \mu \mathrm{m}$ VPP and Pre-RPP film.

\begin{tabular}{|c|c|c|c|c|}
\hline Sample & $\begin{array}{c}\text { Young's } \\
\text { modulus (MPa) }\end{array}$ & $\begin{array}{c}\text { Yield point } \\
(\mathrm{MPa})\end{array}$ & $\begin{array}{c}\text { Tensile fracture } \\
\text { elongation }(\mathrm{mm})\end{array}$ & $\begin{array}{c}\text { Toughness } \\
\left(\mathrm{MJ} / \mathrm{m}^{2}\right)\end{array}$ \\
\hline VPP & 300 & 24 & $\begin{array}{c}115.0 \\
(\min : 110.4 \sim \max : 120.2)\end{array}$ & $\begin{array}{c}2.51 \\
(\min : 2.28 \sim \max : 2.72)\end{array}$ \\
\hline Pre-RPP & 440 & 25 & $\begin{array}{c}11.1 \\
(\min : 3.0 \sim \max : 40.1)\end{array}$ & $\begin{array}{c}0.20 \\
(\min : 0.05 \sim \max : 0.73)\end{array}$ \\
\hline
\end{tabular}

一方 Figure 2 は厚さ $3 \mathrm{~mm}$ の試験片での引張試験結果であ る。この図では装置出力の関係から, 縦軸が断面積で規格化 された応力，横軸が伸びとなっている。この場合引張試験 は3 回実施し, その平均值から評価を行った（なお，図で は複数の試験結果の比較を容易にするために，試験ごとに0 点の位置をずらして表示している)，前報で既に厚さ $3 \mathrm{~mm}$ 程度になると VPP100％と Pre-RPP100％の引張特性に差が ないことを示していたが，今回行った重量ブレンド比率 $6: 4$ および 3:7の試料もほぼ同じ引張特性を示しており，ある程 度の厚みがある試料の引張特性は，バージン品およびリサ イクル品の含有量にほとんど依存しなくなることが判る.
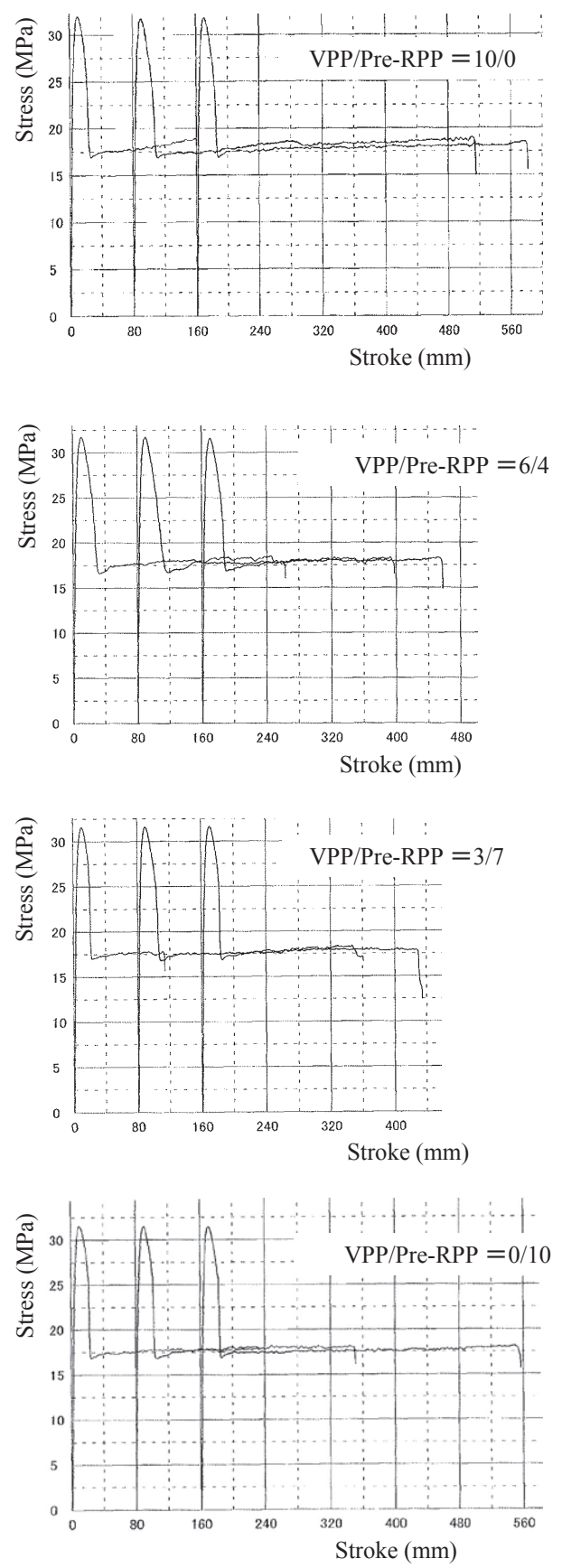

Fig. 2. Stress-Strain charts of various blended ratio samples without UV irradiation. The blended ratios are listed upper right side of each charts. 
Figure 3 はこれらブレンドした試験片を液体チッソ中で破 断した断面のSEM 画像である。前報でVPP $100 \%$ および Pre-RPP 100 \%の破断面が大きく異なることを報告していた が, Pre-RPP が混入することにより，6:4 および 3:7の重量ブ レンド比率で作成した試料の内部構造も大きく荒れるよう になり，Pre-RPP と類似の構造となっていることが判る. 即 ち, 力学特性を見る限りにおいては, ある程度厚みのある試 料に対してはPre-RPP の混入はほとんど問題を引き起こさな
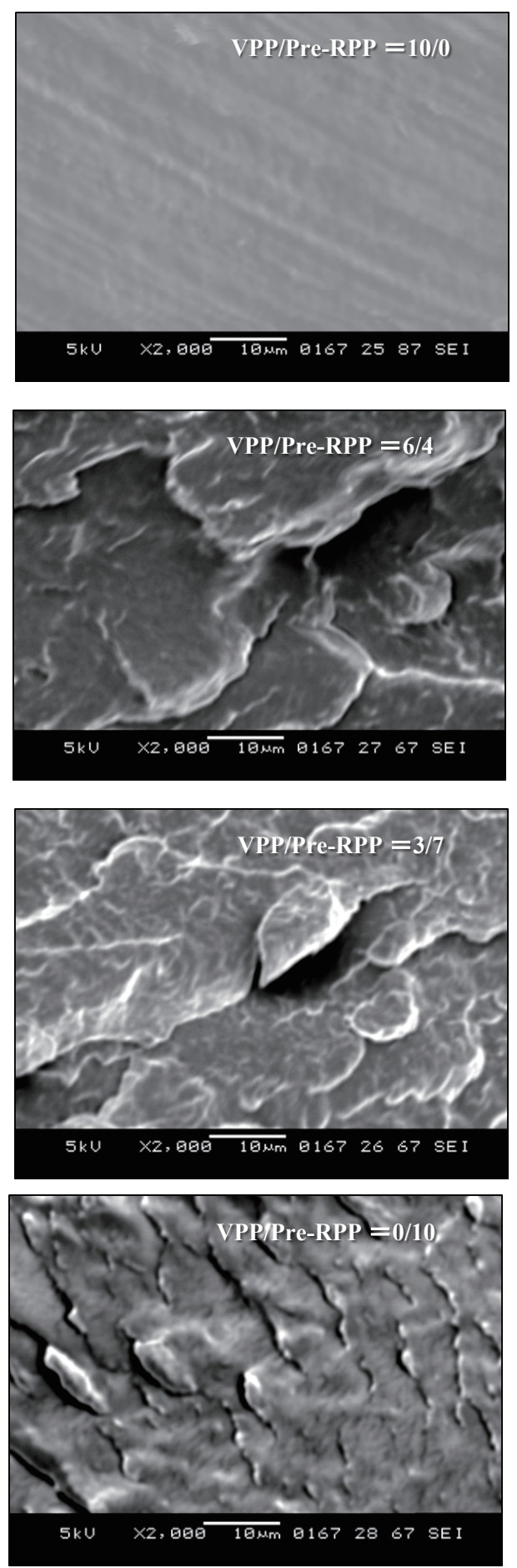

Fig. 3. Cross section SEM images of various blended samples. The blended ratio are listed on the upper right side of each images.
いと考えられるが，内部構造は Pre-RPP の混入により大きく 変化することが判る. 従って, 薄膜の力学特性は, Pre-RPP の混入により，低下するようになることが容易に想像できる.

Figure 4 は Figure 3 の試験に供した厚さ $3 \mathrm{~mm}$ の試験片に 12 時間紫外線照射を行った後の試験片の引張試験の結果で ある。VPPは照射後の引張特性が照射前とほとんど変化し ていないのに対し，Pre-RPPが含まれた試料は引張特性が悪 化しており，また含量が多い試料ほど，早い段階で破断し ていることが判る.

Figure 5 は照射前と 12 時間照射した試料のタフネスの PreRPP 含量依存性を示したものである。この場合も Figure 4 と 同等に 3 回の試験を実施し，その平均から物性の評価を行っ ている（なお，この図でも複数の試験結果の比較を容易にす
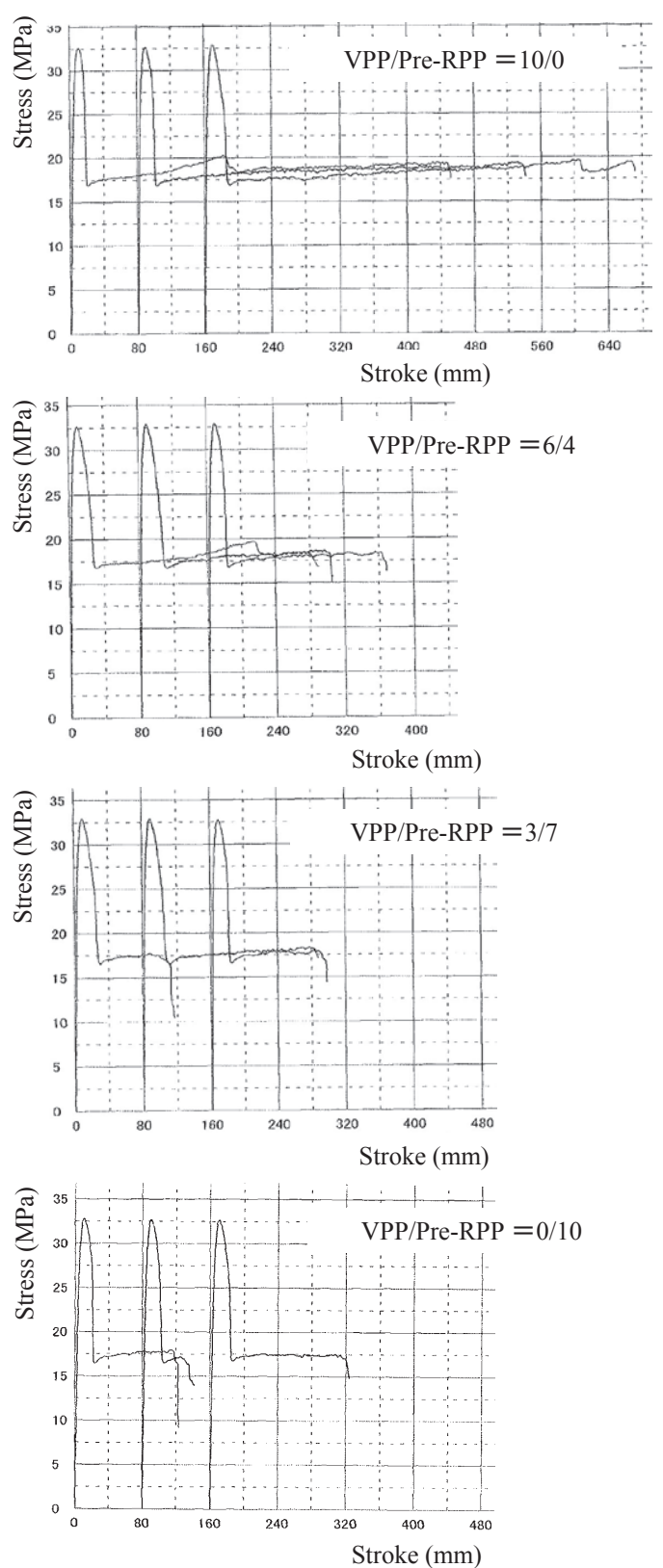

Fig. 4. Stress-Strain charts of various blended ratio samples of 12 hours UV irradiation. The blended ratios are listed upper right side of each charts. 


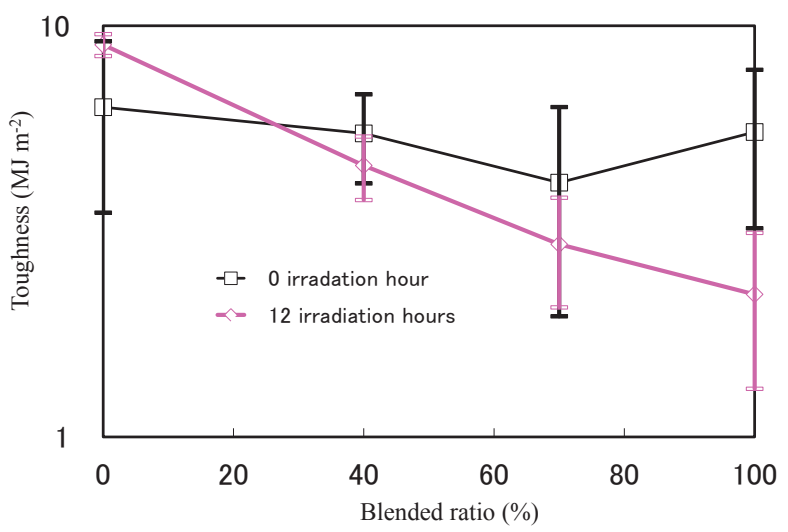

Fig. 5. Blend ratio and UV irradiation time dependence of toughness of various blended ratio samples.

るために，試験ごとに0 点の位置をずらして表示している). 照射前の試料は Pre-RPP 含量依存性がなくほとんど等しい值 であるのに対し，12 時間照射後の試料のタフネスは Pre-RPP の含量にほぼ線形に依存して低下していることが判る。前 報で UV 照射後のタフネスが試料内部のドメイン間に存在し ているタイモレキュール数に指数的に依存することを示し たが，本結果はそのタイモレキュールの数がブレンド比に 一次に依存していることを示しており，今回の研究結果で も非常に単純な関係が成り立っていることが判る。一方で 照射前の試料においては, 内部構造に依存しないスキン層 に力学的な特性が支配されているために，ブレンド比によ らずほぼ同等の結果が出たものと考えられる.

\section{4. まとめ}

前報では試験片の厚みが $3 \mathrm{~mm}$ 程度以上であれば, VPP と Pre-RPP はほぼ同等の力学特性を示すことを明らかにし た.一方でこれら試料の内部構造は大きく異なっており, $100 \mu \mathrm{m}$ 程度の薄膜にした場合にはその影響により, Pre-RPP からの試料の力学特性は大きく劣ることも明らかにした.

本研究結果でも, 厚みがある程度以上ある試料に関して はブレンド比率によらずほぼ同じ特性が得られたが, これは
内部構造に依存しないスキン層の存在のためであり，UV 照 射によりスキン層が破壊されると, 内部のドメインを結び 付けているタイモレキュールの数が一意的に反映され，PreRPP から得られた試料の引張特性が著しく低下することを 見出した。またVPP と Pre-RPP のブレンド品の力学特性は ブレンド比率と単純な一次の比例関係にあることを見出し た。これは前報で見出した引張特性が夕イモレキュール数 に指数的に依存する関係が, VPP と Pre-RPP を各種ブレンド 比率で作成した試料でも成立していることを表している。

これらの結果から, バージン品とリサイクル品のブレン ド試料は，初期特性はほぼ同等のものが得られるが，耐久 性には課題があり，このことを留意した取り扱いが必要で あるということが示唆される。一方で，ブレンドに供する 再生プラスチックのタイモレキュール数を改善することに より, 耐久性も改善される可能性を示唆している.

\section{REFFERENCES}

1) Nishiyama Y, Nippon Gomu Kyokaishi, 81, 388 (2008).

2) Law Concerning the Promotion of Procurement of EcoFriendly Goods and Services by the State and Other Entities (Law on Promoting Green Purchasing), Home page of Ministry of the Environment (http://www.env.go.jp/en/laws/ policy/green/index.html).

3) Home page of Eco Mark Office (http://www.ecomark.jp/ english/index.html).

4) Yao S, Tominaga A, Fujikawa Y, Sekiguchi H, Takatori E, Nihon Reoroji Gakkaishi, 41, 173 (2013).

5) Binsbergen FL, de Lange BGM, Polymer, 9, 23, (1968).

6) Ogino Y, Fukushima H, Takahashi N, Matsuba G, Nishida K, Kanaya T, Macromolecules, 39, 7617 (2006).

7) Hayashi Y, Matsuba G, Zhao Y, Nishida K, Kanaya T, Polymer, 50, 2095 (2009).

8) Housmans JW, Steenbakkers RJA, Roozemond PC, Peters GWM, Meijer HEH, Macromolecules, 42, 5728 (2009).

9) White EEB, Winter HH, Rothstein JP, Rheol Acta, 51, 303 (2012). 